\title{
Robust Course Keeping Control of a Fully Submerged Hydrofoil Vessel without Velocity Measurement: An Iterative Learning Approach
}

\author{
Sheng Liu, Changkui Xu, and Lanyong Zhang \\ College of Automation, Harbin Engineering University, Harbin 150001, China \\ Correspondence should be addressed to Changkui Xu; xuchangkui@hrbeu.edu.cn
}

Received 15 March 2017; Accepted 13 June 2017; Published 20 July 2017

Academic Editor: Rafael Morales

Copyright (C) 2017 Sheng Liu et al. This is an open access article distributed under the Creative Commons Attribution License, which permits unrestricted use, distribution, and reproduction in any medium, provided the original work is properly cited.

\begin{abstract}
This paper proposes a novel robust output feedback control methodology for the course keeping control of a fully submerged hydrofoil vessel. Based on a sampled-data iterative learning strategy, an iterative learning observer is established for the estimation of system states and the generalized disturbances. With the state observer, a feedback linearized iterative sliding mode controller is designed for the stabilization of the lateral dynamics of the fully submerged hydrofoil vessel. The stability of the overall closedloop system is analyzed based on Lyapunov stability theory. Comparative simulation results verify the effectiveness of the proposed control scheme and show the dominance of the disturbance rejection performance.
\end{abstract}

\section{Introduction}

As an advanced marine vehicle, the fully submerged hydrofoil vessel (FSHV) can cruise at a high speed against rough sea waves. The lift force of the hydrofoils generated by the high-speed fluid elevates the ship hull up from the water, which highly reduces the wave resistance and friction on the ship. However, the lift force also destabilizes the open-loop system of the FSHV. Therefore, it is necessary to equip an autopilot for this type of marine vehicles [1-3]. Currently, the commercial control systems equipped on board are based on optimal control theory [4], which has a weak disturbance rejection property. For the sake of the high cruising speed, the nonlinear hydrodynamic damping of the FSHV cannot be neglected $[5,6]$. Therefore, the widely used linear model of marine surface vessels is no longer applicable given the strong coupling between yaw and roll dynamics. Moreover, the model uncertainties and disturbances caused by wind, waves, and currents prevent precise steering of this species of marine vehicle.

The path of marine surface vehicles is usually a straight line or straight lines formed by waypoints at the open sea. Hence, there is little coupling between the longitudinal dynamics and the lateral dynamics. Some literatures present the riding control design of the FSHV [4, 7]. This paper mainly focuses on the steering control of the FSHV.

For the nonlinear steering control of marine vessels, a series of control methodologies have been proposed, such as advanced sliding mode control [8-10], robust control [11, 12], and adaptive control $[13,14]$. But these passive disturbance attenuation control methods may suffer from actuator chattering, system conservation, derivative explosion, and rigorous proof for stability. Intelligent approximation tools such as neural network, fuzzy logic, and SVM are introduced as feedforward components for state estimate and disturbance compensation, but the convergence rate of weight function and the problem of extremum solving still remain to be settled $[6,12]$.

Disturbance rejection control is also widely used in applications of rigid body dynamics and servo systems [1517]. Disturbance observer based control (DOBC) approaches provide an active way to handle disturbances and improve the robustness of the closed-loop systems. The effectiveness of DOBC has been shown in many fields such as manipulator tracking control [18], missile guidance and control [19$21]$, and motor control [22, 23]. However, traditional DOB methodology cannot be used in nonlinear dynamics due to the limitation of linear system theory, and the low pass filter 
must be designed strictly such that the convergence of the disturbance estimate can be guaranteed [16].

Most of the methodologies for motion control of marine vehicles in the existing literatures employ full-state feedback. In many practical applications, only angle signals can be measured and utilized [24-32] since the sensor information of angle velocity usually contains irregular noises caused by the environment and properties of electric components, which are difficult to filter $[5,33]$. Therefore, it is necessary to design a state observer to make state estimation for the system. State observer based control schemes have been developed for many species of nonlinear systems such as nonlinear time-delay systems [34, 35], Lipschitz nonlinear systems $[24,26,36]$, and other structured systems $[15,27$, 28]. According to the design theory, state observers can be classified, for example, as Luenberger observer [29, 36], highgain observer [30], and sliding mode observer [31, 32]. For nonlinear systems with model uncertainties and external disturbances, there are the following disadvantages of these above-mentioned state observers.

(1) In most control engineering applications, the system structures do not match these observers very well, so the observers require complicated coordinated transformations.

(2) Many state observer methodologies are designed for SISO systems, but the practicality and stability of these methodologies for MIMO systems still need to be further discussed.

(3) Most of these observers estimate only the system states, while the disturbance estimate could not be overall considered.

The course keeping control of the FSHV suffers severely from model uncertainties and wave disturbances. Therefore, it is of great necessity to design an observer which is able to estimate system states as well as the generalized disturbances integratedly. Furthermore, in order to guarantee the disturbance rejection performance of the control scheme, the feedback controller of the inner loop should also achieve disturbance attenuation properties, such that the residual error of the disturbance estimate can be compensated through a composite strategy.

In this paper, a novel output feedback control methodology is proposed for the course keeping control of the FSHV based on a sampled-data iterative learning approach. An iterative learning observer is established for the state estimation as well as generalized disturbances. Then a sliding model controller with an iterative learning sliding manifold is presented for the stabilization of the lateral dynamics of the FSHV. The design of the iterative sliding surface introduces a memory effect for the controller, which includes both the current and past information of the system states and outperforms the standard sliding mode control in the improvement of the transient performance.

The rest of the paper is organized as follows. In Section 2, the mathematical model of the lateral dynamics of the FSHV is established. In Section 3, an observer based sliding mode control is proposed based on iterative learning approach. Then we analyze the Lyapunov stability of the overall closed-loop system in Section 4. Simulation is carried out in Section 5 to validate the effectiveness of the proposed methodology, followed by Conclusions in Section 6 .

\section{Problem Formulation}

A typical configuration of a fully submerged hydrofoil vessel is shown in Figure 1 [4]. The T-shaped bow foil is equipped with two controlled flaps, acting together. The aft foil has a pair of central flaps and two pairs of ailerons. Struts of the aft foil are equipped with rudders, which are used for roll and yaw dynamics together with the ailerons. The bow foil and the central part of the aft foil are for longitudinal motion control.

Course keeping control, or so-called ship heading control, is the primary task of the autopilots of ships. The control objective of course keeping control is to stabilize the yaw angle to a desired heading angle. As to the course keeping control for conventional marine surface vessels, the roll dynamics is rarely considered due to the weakness of the control actuators for roll dynamics. The roll restoring moments provide static stability, which the FSHV does not have. Therefore, it is necessary to take the roll dynamics into consideration for the course keeping control design for the FSHV.

The surge speed $u$ is usually controlled by an individual propulsion system and is kept at a fixed speed $u_{0}$ when a ship is maneuvered in the course keeping mode. Accordingly, a 2DOF steering model of the FSHV is shown as

$$
\begin{aligned}
\dot{\eta} & =J(\eta) v \\
M \dot{v}+C\left(u_{0}, v\right) v+D\left(u_{0}, v\right) v+G(\eta) \eta & =b u+\tau_{d},
\end{aligned}
$$

where $\eta=[\phi, \psi]^{T}$, in which $\phi$ and $\psi$ denote the roll angle and heading angle of the FSHV with coordinates in the earth-fixed frame, respectively; $v=[p, r]^{T}$, in which $p$ and $r$ represent the angular velocities with coordinates in the body-fixed frame, respectively; $J=\left[\begin{array}{cc}1 & 0 \\ 0 & \cos \phi\end{array}\right]$ is the Jacobian transformation matrix related to the above frames; $M=\left[\begin{array}{cc}I_{x}-K_{\dot{p}} & m x_{g}-K_{\dot{r}} \\ m x_{g}-N_{\dot{p}} & I_{z}-N_{\dot{r}}\end{array}\right]$ is the inertia including added mass; and $C\left(u_{0}, v\right)=\left[\begin{array}{cc}0 & 0 \\ 0 & m x_{g} u_{0}\end{array}\right]$ denotes the Coriolis and centripetal matrix. Selecting the origin point of the body-fixed frame at the center of gravity yields $x_{g}=0 . D\left(u_{0}, \nu\right)$ is the coupling interaction caused by the nonlinear hydrodynamic damping, which is defined as $D=D_{L}+D_{N} \cdot D_{L}=\left[\begin{array}{l}-K_{p}-K_{r} \\ -N_{p}-N_{r}\end{array}\right]$ stands for the linear part and $D_{N}=\left[\begin{array}{ll}0 & -K_{r \phi \phi} \phi^{2} \\ 0 & -N_{r r \phi} r \phi\end{array}\right]$ represents the nonlinear damping, respectively. $K_{p}, K_{r \phi \phi}, K_{r}, K_{r \phi \phi}$, and $N_{r \phi \phi}, N_{p}$, $N_{r}, N_{r r \phi}$ are the hydrodynamic coefficients. In the low-speed mode, the high-order terms and coupling interactions among the forces from each DOF are not considered. Therefore, $D\left(u_{0}, \nu\right)$ is often regarded as a linear term and even cancelled in many literatures. However, given the high-speed character of the FSHV, the nonlinear damping hydrodynamics can no longer be neglected. $G(\eta)$ represents the gravity term which is described as $G(\eta)=\left[W \overline{G M}_{T}, 0\right]^{T}$, where $W=m g$ is the weight and $\overline{G M}_{T}$ is the transverse metacenter height [37]. 

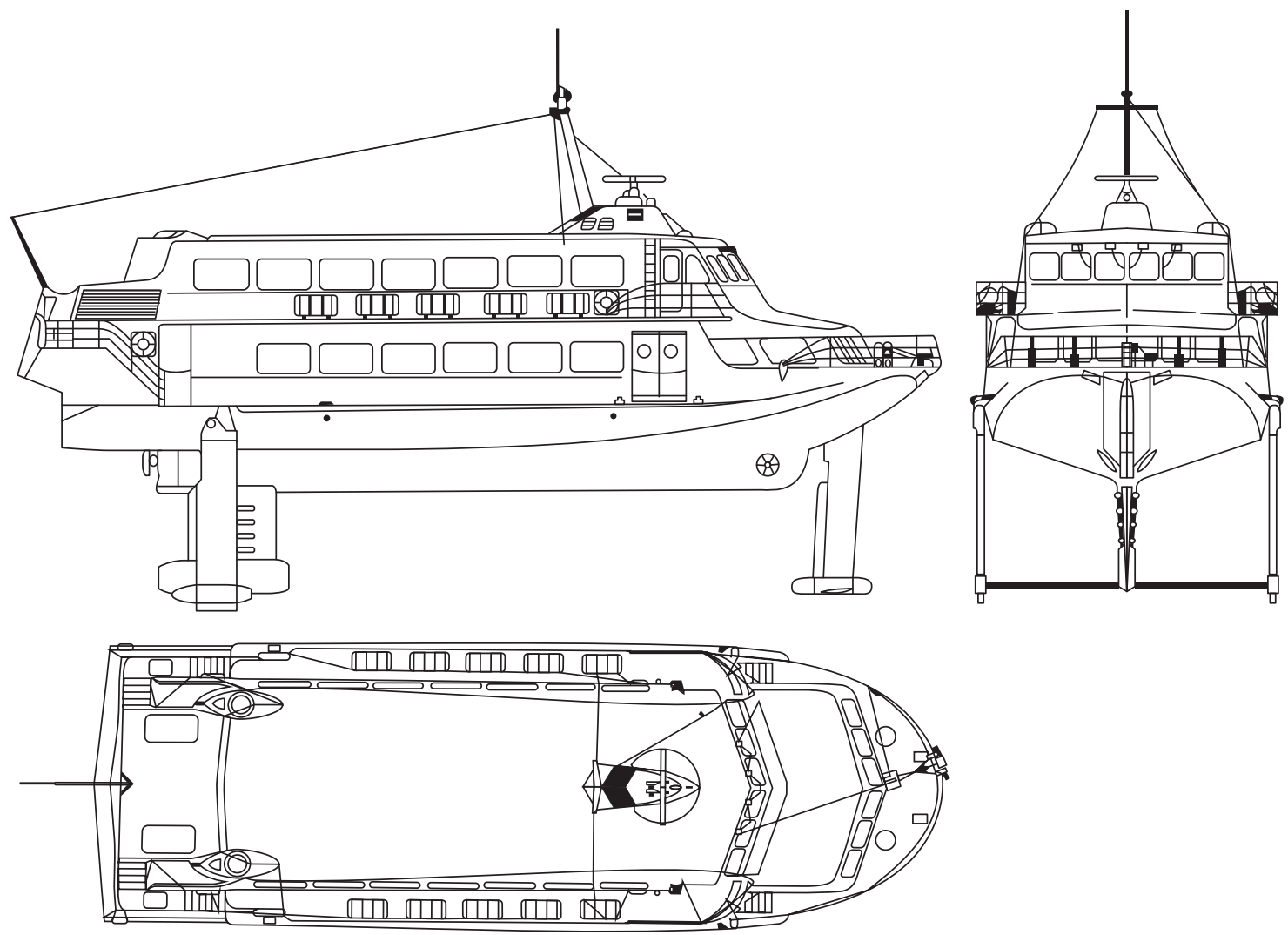

FIGURE 1: Fully submerged hydrofoil vessel.

$b=\left[\begin{array}{ll}K_{\delta_{R}} & K_{\delta_{A}} \\ N_{\delta_{R}} & N_{\delta_{A}}\end{array}\right]$ is the control moment coefficient matrix subjected to the control surface, and $u=\left[\delta_{R}, \delta_{A}\right]^{T}$ is the control input, where $\delta_{R}$ and $\delta_{A}$ represent the rudder angle and aileron angle of the hydrofoil system, respectively. As for the modeling of the FSHV, it is reasonable to select the origin point of the body-fixed frame at the center of gravity, thus yielding $x_{g}=y_{g}=z_{g}=0$.

Considering the course keeping problem of the FSHV, the first equation in (1) can be simplified as $\dot{\eta}=v$. By defining $x_{1} \triangleq \eta, x_{2} \triangleq v$, the steering model of the FSHV can be regarded as a second-order system as

$$
\begin{aligned}
& \dot{x}_{1}=x_{2} \\
& \dot{x}_{2}=F\left(x_{1}, x_{2}\right)+\xi\left(x_{1}, x_{2}\right)+\bar{b} u+\bar{\tau}_{d},
\end{aligned}
$$

where

$$
\begin{aligned}
& F\left(x_{1}, x_{2}\right) \\
& =-M^{-1}\left[C\left(u_{0}, x_{2}\right) x_{2}+D_{L}\left(u_{0}, x_{2}\right) x_{2}+G\left(x_{1}\right) x_{1}\right] \\
& \xi\left(x_{1}, x_{2}\right)=-M^{-1} D_{N}\left(u_{0}, x_{2}\right) x_{2}, \\
& \bar{b}=M^{-1} b \\
& \bar{\tau}_{d}=M^{-1} \tau_{d} .
\end{aligned}
$$

If the model uncertainties are considered in the modeling and control of the FSHV, the following notations are introduced:

$$
\begin{gathered}
F\left(x_{1}, x_{2}\right)=F_{0}\left(x_{1}, x_{2}\right)+F_{\Delta}\left(x_{1}, x_{2}\right), \\
\xi\left(x_{1}, x_{2}\right)=\xi_{0}\left(x_{1}, x_{2}\right)+\xi_{\Delta}\left(x_{1}, x_{2}\right),
\end{gathered}
$$

where subscript 0 denotes the nominal part of the corresponding matrix and the subscript $\Delta$ represents the perturbed part of the system dynamics. The yaw/roll dynamics of the FSHV with model uncertainties can be rewritten as follows:

$$
\begin{aligned}
& \dot{x}_{1}=x_{2} \\
& \dot{x}_{2}=F_{0}\left(x_{1}, x_{2}\right)+\xi_{0}\left(x_{1}, x_{2}\right)+\bar{b} u+f_{d}(t),
\end{aligned}
$$

where $f_{d}(t)=F_{\Delta}\left(x_{1}, x_{2}\right)+\xi_{\Delta}\left(x_{1}, x_{2}\right)+\bar{\tau}_{d}$ is the generalized disturbances of the system.

Remark 1. When ships sail at a fixed speed, $M(\cdot), C(\cdot), D_{L}(\cdot)$, and $G(\cdot)$ are linear matrices with constant element parameters, so $F_{0}\left(x_{1}, x_{2}\right)$ is also a linear function, while $\zeta_{0}\left(x_{1}, x_{2}\right)$ represents the nonlinear damping of the coupling hydrodynamics of the FSHV.

Hence, the control objective is to design an observer based output feedback controller for the course keeping of the FSHV using an iterative learning approach. The control structure of the system is summarized in Figure 2. For the 


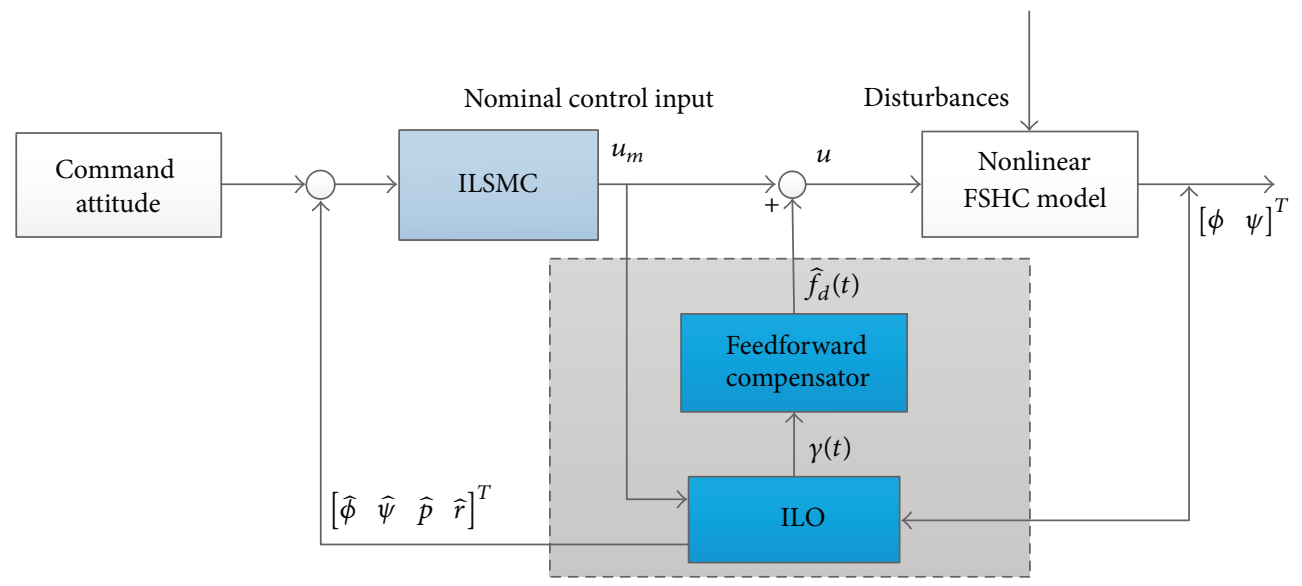

FIgURE 2: Control structure for the course keeping of FSHV.

subsequent analysis, the following assumptions are carried out for convenience.

Assumption 2 (see $[25-28,37]$ ). The nonlinear function $\xi(\cdot)$ is continuously differentiable and satisfies Lipschitz condition with Lipschitz constant $\sigma$; that is,

$$
\|\xi(x)-\xi(\widehat{x})\| \leq \sigma\|x-\widehat{x}\| .
$$

Remark 3. For marine vehicle systems, the high-order coupling hydrodynamics is sufficiently smooth. Therefore, it is reasonable that the nonlinear function $\xi(\cdot)$ satisfies Lipschitz condition.

Assumption 4. The disturbance $f_{d}(t)$ is bounded; namely, $\left\|f_{d}(t)\right\| \leq \bar{f}_{d}$.

\section{Output Feedback Control Design of the FSHV}

3.1. Iterative Learning Observer Design. In this section, an iterative learning observer (ILO) is established for estimation of system states as well as the disturbances. To facilitate the subsequent design, the system dynamics in (5) are rewritten into a generalized state space model as

$$
\begin{aligned}
& \dot{x}=A x+\xi(x)+B u+E f_{d}(t) \\
& y=C x
\end{aligned}
$$

where $A=\left[\begin{array}{cc}0 & I \\ -M^{-1} G-M^{-1}\left(C+D_{L}\right)\end{array}\right], \xi(x)=\left[\begin{array}{c}0 \\ -M^{-1} D_{N} x_{2}\end{array}\right], B=\left[\begin{array}{l}0 \\ b\end{array}\right]$, $C=\left[\begin{array}{ll}I & 0\end{array}\right], E=\left[\begin{array}{l}0 \\ I\end{array}\right]$, and $x=\left[\begin{array}{ll}x_{1} & x_{2}\end{array}\right]^{T}, y=x_{1}$.

Based on (7), an ILO is designed as

$$
\begin{aligned}
\dot{\hat{x}} & =A \hat{x}+\xi(\widehat{x})+B u(t)+L(y-\hat{y})+E \gamma(t) \\
\gamma(t) & =\mu_{1} \gamma(t-\tau)+\mu_{2}[y(t)-\hat{y}(t)] \\
\hat{y}(t) & =C \hat{x},
\end{aligned}
$$

where $\hat{x}$ is the estimation value of $x, \widehat{y}(t)$ is the estimation of system output at time $t, \tau$ is the sampling time interval, $\gamma$ is called ILO input, $\gamma(t)$ is the current ILO input and $\gamma(t-\tau)$ is the ILO input at the last sampling period. $L$ and $\mu_{i}(i=$ $1,2)$ are two gain matrices with appropriate dimensions to be determined.

Remark 5. It can be seen from (8) that if the gain matrix $\mu_{1}$ is selected as a zero matrix, the ILO will degenerate into a conventional Luenberger observer. Therefore, zero matrix should be avoided for the gain tuning in order to maintain the capability of the estimation for the generalized disturbance.

Remark 6. It is necessary to clarify that the ILO input $\gamma(t)$ proposed in (8) is not a discrete-time equation since the sampling time $\tau$ can be chosen as any value theoretically. $\tau$ used in the control design in Part B also matches this instruction, which can be further indicated by the Lyapunov function in stability analysis.

Remark 7. Compared with the conventional adaptive state observers, the proposed ILO has several advantages. It is able to estimate both system states and time-varying disturbance at the same time. Additionally, persistence of excitation (PE) is not required, which is necessary for the adaptive observers to update the estimation law online.

Subtracting (8) from (7) results in the estimation error dynamics as

$$
\dot{\tilde{x}}=(A-L C) \tilde{x}+[\xi(x)-\xi(\widehat{x})]+E\left[f_{d}(t)-\gamma(t)\right],
$$

where $\tilde{x} \triangleq x-\widehat{x}$ is the estimate error.

The disturbance estimation error $\widetilde{d}$ and an auxiliary variable $d_{\tau}$ are defined as follows:

$$
\begin{aligned}
\tilde{d} & =f_{d}(t)-\gamma(t), \\
d_{\tau} & =f_{d}(t)-\mu_{1} f_{d}(t-\tau),
\end{aligned}
$$

and then it yields

$$
\begin{aligned}
\tilde{d}(t) & =d(t)-\mu_{1} \gamma(t-\tau)-\mu_{2} C \tilde{x}(t) \\
& =\mu_{1} \tilde{d}(t-\tau)-\mu_{2} C \tilde{x}(t)+d_{\tau} .
\end{aligned}
$$


By substituting (11) into (9), it yields

$$
\begin{aligned}
\dot{\tilde{x}}= & (A-L C) \tilde{x}+E \mu_{1} \tilde{d}(t-\tau)-E \mu_{2} C \tilde{x}(t)+E d_{\tau} \\
& +[\xi(x)-\xi(\widehat{x})] .
\end{aligned}
$$

Theorem 8. Given the system dynamics in (7) with the proposed ILO designed in (8), the state estimate error is bounded if the following conditions hold:

$$
\begin{aligned}
(A-L C)^{T} P+P(A-L C) & =-Q, \\
P E & =\rho\left(\mu_{2} C\right)^{T}, \quad \rho>1, \\
0 & <\left(\rho+m^{2}\right) \mu_{1}^{T} \mu_{1} \leq I .
\end{aligned}
$$

Proof. Define the following Lyapunov function candidate:

$$
V_{1}=\tilde{x}^{T}(t) P \tilde{x}(t)+\int_{t-\tau}^{t} \tilde{d}^{T}(\alpha) \tilde{d}(\alpha) d \alpha,
$$

where $P$ is a positive definite symmetric matrix.

Based on (9) and (12), differentiating $V_{1}$ with respect to time yields

$$
\begin{aligned}
\dot{V}_{1}= & \widetilde{x}^{T}\left[(A-L C)^{T} P+P(A-L C)\right] \tilde{x} \\
& +2 \tilde{x}^{T}(t) P E \mu_{1} \tilde{d}(t-\tau)-2 \widetilde{x}(t) P E \mu_{2} C \tilde{x}(t) \\
& +2 \tilde{x}^{T}(t) P E d_{\tau}(t)-\varepsilon \tilde{d}^{T}(t) \tilde{d}(t)+\rho \tilde{d}^{T}(t) \tilde{d}(t) \\
& -\tilde{d}^{T}(t-\tau) \tilde{d}(t-\tau)+2 \widetilde{x}^{T}(t) P[\xi(x)-\xi(\widehat{x})],
\end{aligned}
$$

where $\rho$ and $\varepsilon$ are positive constants and $\rho-\varepsilon=1$.

Substituting (11) into (15), we can obtain

$$
\begin{aligned}
\dot{V}_{1}= & \tilde{x}^{T}\left[(A-L C)^{T} P+P(A-L C)\right] \tilde{x} \\
& +2 \tilde{x}^{T}(t) P E \mu_{1} \tilde{d}(t-\tau) \\
& +2 \tilde{x}^{T}(t) P[\xi(x)-\xi(\widehat{x})]-2 \widetilde{x}(t) P E \mu_{2} C \tilde{x}(t) \\
& +2 \tilde{x}^{T}(t) P E d_{\tau}(t)-\varepsilon \tilde{d}^{T}(t) \tilde{d}(t) \\
& +\rho \tilde{d}(t-\tau) \mu_{1}^{T} \mu_{1} \tilde{d}(t-\tau)+\rho d_{\tau}^{T} d_{\tau} \\
& +2 \rho \tilde{d}^{T}(t-\tau) \mu_{1}^{T} d_{\tau}(t)-2 \rho \tilde{x}^{T}\left(\mu_{2} C\right)^{T} d_{\tau}(t) \\
& -\tilde{d}^{T}(t-\tau) \tilde{d}(t-\tau) .
\end{aligned}
$$

For any $Q=Q^{T}>0$, there exists $P=P^{T}>0$ satisfying the following Riccati equation:

$$
\begin{aligned}
(A-L C)^{T} P+P(A-L C) & =-Q, \\
P E & =\rho\left(\mu_{2} C\right)^{T} .
\end{aligned}
$$

Then it yields

$$
\begin{aligned}
\dot{V}_{1} \leq & -\lambda_{\min }(Q)\|\tilde{x}\|^{2}-\varepsilon\|\tilde{d}(t)\|^{2}-\tilde{d}^{T}(t-\tau) \tilde{d}(t-\tau) \\
& +\rho \tilde{d}^{T}(t-\tau) \mu_{1}^{T} \mu_{1} \tilde{d}(t-\tau) \\
& +2 \rho \tilde{d}(t-\tau) \mu_{1}^{T} d_{\tau}(t)+\rho \bar{d}_{\tau}^{2}+2 \eta\|P\|\|\tilde{x}\|^{2} .
\end{aligned}
$$

By using the inequality in

$$
\begin{aligned}
2 \rho \widetilde{d}^{T}(t-\tau) \mu_{1}^{T} d_{\tau}(t) \leq & m^{2} \widetilde{d}^{T}(t-\tau) \mu_{1}^{T} \mu_{1} \tilde{d}(t-\tau) \\
& +\frac{\rho^{2}}{m^{2}} d_{\tau}^{T}(t) d_{\tau}(t),
\end{aligned}
$$

It follows that

$$
\begin{aligned}
\dot{V}_{1} \leq & -\lambda_{\min }(Q)\|\tilde{x}\|^{2}-\varepsilon\|\tilde{d}(t)\|^{2} \\
& +\tilde{d}^{T}(t-\tau)\left[\left(\rho+m^{2}\right) \mu_{1}^{T} \mu_{1}-I\right] \tilde{d}(t-\tau) \\
& +\left(\rho+\frac{\rho^{2}}{m^{2}}\right) \bar{d}_{\tau}^{2}+2 \eta \lambda_{\max }(P)\|\tilde{x}\|^{2} ;
\end{aligned}
$$

namely,

$$
\begin{aligned}
\dot{V}_{1} \leq & -k\|\tilde{x}\|^{2}-\varepsilon\|\tilde{d}(t)\|^{2}+\left(\rho+\frac{\rho^{2}}{m^{2}}\right)\left\|\bar{d}_{\tau}\right\|^{2} \\
& +\tilde{d}^{T}(t-\tau)\left(\left(\rho+m^{2}\right) \mu_{1}^{T} \mu_{1}-I\right) \tilde{d}(t-\tau),
\end{aligned}
$$

where $k=\lambda_{\min }(Q)-2 \eta \lambda_{\max }(P)>0$.

If $0<\left(\rho+m^{2}\right) \mu_{1}^{T} \mu_{1} \leq I$ holds, the estimation error as well as the generalized disturbances is uniformly ultimately bounded (UUB) [38].

3.2. Observer Based Iterative Sliding Mode Controller Design. As to the controller design, an ILO based sliding mode controller is proposed for the output feedback course keeping control problem of the FSHV based on an iterative learning sliding surface. Before the controller design, we first make the following transformation.

By utilizing the feedback linearization method and replacing the system states with the estimated values, the system model in (2) can be rewritten as

$$
\begin{aligned}
& \dot{\hat{x}}_{1}=\widehat{x}_{2}, \\
& \dot{\hat{x}}_{2}=F_{0}\left(\widehat{x}_{1}, \widehat{x}_{2}\right)+\chi+f_{d}(t),
\end{aligned}
$$

where $\chi$ is a virtual control variable defined as

$$
\chi=\xi_{0}\left(\widehat{x}_{1}, \widehat{x}_{2}\right)+\bar{b} u
$$

Based on the proposed ILO, the estimate of $f_{d}(t)$ can be obtained as $\widehat{f}_{d}=\gamma$.

By using $\widehat{f}_{d}$ as a feedforward compensator, the virtual control can be designed as $\chi=\chi_{s}-\widehat{f}_{d}$. Then it yields

$$
\begin{aligned}
& \dot{\hat{x}}_{1}=\hat{x}_{2} \\
& \dot{\hat{x}}_{2}=F_{0}\left(\widehat{x}_{1}, \widehat{x}_{2}\right)+\chi_{s}+e_{d},
\end{aligned}
$$

where $e_{d}$ is the residual error of $\widehat{f}_{d}$ and $\left|e_{d}\right| \leq \bar{e}_{d}$.

Based on (24), the iterative learning sliding mode controller can be designed as follows. 
Define a novel sliding surface with an iterative item in the following form:

$$
s=\widehat{x}_{2}-K \widehat{x}_{1}-K_{\tau} \widehat{x}_{1}(t-\tau)
$$

where $K, K_{\tau} \in R^{2 \times 2}$ are sliding parameters to be designed.

Remark 9. According to (25), it is clear that if the time interval $\tau$ is chosen as $\tau=0$, the sliding surface will become $s=\widehat{x}_{2}-\left(K+K_{\tau}\right) \hat{x}_{1}$, which is actually a conventional linear sliding surface. Hence, the existence of $\tau$ implies the improvement of the dynamic performance of the iterative learning sliding surface.

Let $s=0$, then it yields

$$
\dot{\hat{x}}_{1}=K \widehat{x}_{1}+K_{\tau} \widehat{x}_{1}(t-\tau) .
$$

Define the Lyapunov function $V_{2}$ as

$$
V_{2}=\widehat{x}_{1}^{T} \Phi \widehat{x}_{1}+\int_{t-\tau}^{t} \widehat{x}_{1}^{T}(\omega) Z \widehat{x}_{1}(\omega) d \omega
$$

where $\Phi, Z$ are positive definite matrices.

Differentiating $V_{2}$ with respect to time yields

$$
\begin{aligned}
\dot{V}_{2}= & \dot{x}_{1}^{T} \Phi x_{1}+x_{1}^{T} \Phi \dot{x}_{1}+x_{1}^{T}(t) Z x_{1}(t) \\
& -x_{1}^{T}(t-\tau) Z x_{1}(t-\tau) .
\end{aligned}
$$

Substituting (26) into (28), we can obtain

$$
\begin{aligned}
\dot{V}_{2}= & \widehat{x}_{1}^{T}\left(K^{T} \Phi+\Phi K\right) \widehat{x}_{1}+\widehat{x}_{1}^{T} \Phi K_{\tau} \widehat{x}_{1}(t-\tau) \\
& +\widehat{x}_{1}^{T}(t-\tau) K_{\tau}^{T} \Phi \widehat{x}_{1}(t-\tau)+\widehat{x}_{1}^{T} Z \widehat{x}_{1} \\
& -\widehat{x}_{1}^{T}(t-\tau) Z \hat{x}_{1}(t-\tau) .
\end{aligned}
$$

Denote $\Lambda \triangleq\left[\widehat{x}_{1}^{T}(t) \widehat{x}_{1}^{T}(t-\tau)\right]^{T}$; then (29) can be rewritten as

$$
\dot{V}_{2}=\Lambda^{T}\left[\begin{array}{cc}
K^{T} \Phi+\Phi K+Z & \Phi K_{\tau} \\
\Phi K_{\tau} & -Z
\end{array}\right] \Lambda .
$$

By appropriately tuning $K, K_{\tau}, \Phi$, and $Z$, there exists a positive definite matrix $\Gamma$ such that

$$
\left[\begin{array}{cc}
K^{T} \Phi+\Phi K+Z & \Phi K_{\tau} \\
\Phi K_{\tau} & -Z
\end{array}\right]=-\Gamma .
$$

Then it yields

$$
\dot{V}_{2}=-\Lambda^{T} \Gamma \Lambda \leq-\lambda_{\min }(\Gamma)\|\Lambda\|^{2},
$$

which indicates that the iterative learning sliding motion (25) is asymptotically stable. Therefore, once the system trajectory reaches the sliding surface, it can be kept at the sliding surface.

Based on the proposed sliding surface, the control law $\chi_{s}$ can be designed as

$$
\begin{aligned}
\chi_{s}= & -\left[F_{0}\left(\hat{x}_{1}, \hat{x}_{2}\right)-K \hat{x}_{2}-K_{\tau} \hat{x}_{2}(t-\tau)+\alpha s\right] \\
& -\bar{e}_{d} \operatorname{sgn}(s),
\end{aligned}
$$

where $\alpha$ is a positive scalar.
Then the final control input $u$ is obtained as

$$
u=\bar{b}^{-1}\left[\chi_{s}\left(\hat{x}_{1}, \widehat{x}_{2}\right)-\widehat{f}_{d}-\xi_{0}\left(x_{1}, x_{2}\right)\right] .
$$

Therefore, the iterative learning sliding mode controller for the course keeping of the FSHV in an output feedback scheme is implemented.

\section{Stability Analysis}

The closed-loop stability of the observer-controller structure of system (5) is analyzed in this part.

Theorem 10. Given the system model for the course keeping control of the FSHV in (5), with the ILO proposed in (8) and the feedback linearization based iterative learning sliding mode controller in (34), uniformly ultimate boundedness can be guaranteed for the closed-loop system at the equilibrium point.

Proof. The Lyapunov function of the closed-loop system is selected as

$$
V_{3}=V_{1}+\frac{1}{2} s^{T} s
$$

Differentiating $V_{3}$ with respect to time, we can obtain

$$
\begin{aligned}
\dot{V}_{3}= & \tilde{x}^{T}\left[(A-L C)^{T} P+P(A-L C)\right] \tilde{x} \\
& +2 \widetilde{x}^{T}(t) P E \mu_{1} \tilde{d}(t-\tau)-2 \widetilde{x}(t) P E \mu_{2} C \widetilde{x}(t) \\
& +2 \tilde{x}^{T}(t) P E d_{\tau}(t)-\varepsilon \tilde{d}^{T}(t) \tilde{d}(t)+\rho \tilde{d}^{T}(t) \tilde{d}(t) \\
& -\tilde{d}^{T}(t-\tau) \tilde{d}(t-\tau)+2 \tilde{x}^{T}(t) P[\xi(x)-\xi(\widehat{x})] \\
& +s^{T} \dot{s} .
\end{aligned}
$$

Based on the results of (21), (24), and (25), substituting the control law (34) into (36), we have

$$
\begin{aligned}
\dot{V}_{3} \leq & -k\|\tilde{x}\|^{2}-\varepsilon\|\tilde{d}(t)\|^{2}+\left(\rho+\frac{\rho^{2}}{m^{2}}\right) \bar{d}_{\tau}^{2} \\
& +\tilde{d}^{T}(t-\tau)\left(\left(\rho+m^{2}\right) \mu_{1}^{T} \mu_{1}-I\right) \tilde{d}(t-\tau) \\
& +s\left[e_{d}-\bar{e}_{d} \operatorname{sgn}(s)-\alpha s\right] \\
\dot{V}_{3} \leq & -k\|\tilde{x}\|^{2}-\varepsilon\|\tilde{d}(t)\|^{2}+\left(\rho+\frac{\rho^{2}}{m^{2}}\right) \bar{d}_{\tau}^{2} \\
& +\tilde{d}^{T}(t-\tau)\left(\left(\rho+m^{2}\right) \mu_{1}^{T} \mu_{1}-I\right) \tilde{d}(t-\tau) \\
& +\|s\|\left\|e_{d}\right\|-\bar{e}_{d} s \operatorname{sgn}(s)-\alpha\|s\|^{2} \\
\dot{V}_{3} \leq & -k\|\tilde{x}\|^{2}-\varepsilon\|\tilde{d}(t)\|^{2}-\alpha\|s\|^{2}+\left(\rho+\frac{\rho^{2}}{m^{2}}\right) \bar{d}_{\tau}^{2} \\
& +\tilde{d}^{T}(t-\tau)\left(\left(\rho+m^{2}\right) \mu_{1}^{T} \mu_{1}-I\right) \tilde{d}(t-\tau) .
\end{aligned}
$$


TABLE 1: Model parameters of the FSHV.

\begin{tabular}{lcc}
\hline Parameter & Value & SI-unit \\
\hline$u_{0}$ & 23.15 & $\mathrm{~m} / \mathrm{s}$ \\
$m$ & $2.62 * 10^{5}$ & $\mathrm{~kg}$ \\
$I_{x}$ & $2.59 * 10^{5}$ & $\mathrm{kgm}^{2}$ \\
$I_{z}$ & $1.47 * 10^{7}$ & $\mathrm{kgm}^{2}$ \\
$\overline{G M_{T}}$ & 0.025 & $\mathrm{~m}$ \\
$K_{p}$ & $-13.0354 * 10^{5}$ & $\mathrm{kgm}^{2} / \mathrm{s}$ \\
$K_{r}$ & $-2.4864 * 10^{5}$ & $\mathrm{kgm}^{2} / \mathrm{s}$ \\
$K_{r r \phi}$ & $-19.0883 * 10^{5}$ & $\mathrm{kgm}^{2} / \mathrm{s}$ \\
$K_{r \phi \phi}$ & $12.5615 * 10^{5}$ & $\mathrm{kgm}^{2} / \mathrm{s}$ \\
$N_{p}$ & $-0.2182 * 10^{7}$ & $\mathrm{kgm}^{2} / \mathrm{s}$ \\
$N_{r}$ & $-1.3818 * 10^{7}$ & $\mathrm{kgm}^{2} / \mathrm{s}$ \\
$N_{r r \phi}$ & $0.9261 * 10^{7}$ & $\mathrm{kgm}^{2} / \mathrm{s}$ \\
$N_{r \phi \phi}$ & $-1.5141 * 10^{7}$ & $\mathrm{kgm}^{2} / \mathrm{s}$ \\
$K_{\delta_{R}}$ & -1.046 & $\mathrm{kgm}^{2} / \mathrm{s}$ \\
$K_{\delta_{A}}$ & 5.84 & $\mathrm{kgm}^{2} / \mathrm{s}$ \\
$N_{\delta_{R}}$ & 0.3925 & $\mathrm{kgm}^{2} / \mathrm{s}$ \\
$N_{\delta_{A}}$ & -0.2308 & $\mathrm{kgm}^{2} / \mathrm{s}$ \\
\hline
\end{tabular}

Together with the results of Theorem 8 , if the conditions

$$
\begin{aligned}
(A-L C)^{T} P+P(A-L C) & =-Q, \\
P E & =\rho\left(\mu_{2} C\right)^{T}, \quad \rho>1, \\
0 & <\left(\rho+m^{2}\right) \mu_{1}^{T} \mu_{1} \leq I, \\
{\left[\begin{array}{cc}
K^{T} \Phi+\Phi K+Z & \Phi K_{\tau} \\
\Phi K_{\tau} & -Z
\end{array}\right] } & =-\Gamma
\end{aligned}
$$

hold, the equilibrium point of system (5) is uniformly ultimately bounded.

\section{Simulation}

In this section, a mathematical model of a FSHV $[2,3]$ is applied to validate the performance of the proposed approach. The physical parameters of the FSHV are given in Table 1.

The nominal system model with norm-bounded perturbation items is used to simulate the model uncertainties; namely, $p_{\Delta j j}=p_{j j}+0.15 p_{j j} \cdot \operatorname{rand}(-1,1)$, where $p_{\Delta j j}$ is the parameter with perturbation and $p_{j j}$ is the nominal model parameter of (1). To simulate the wave disturbance, the Pierson-Moskowitz (PM) spectrum is selected as the standard wave energy spectrum [39], which can be expressed as

$$
S(\omega)=A \omega^{-5} \exp \left(-B \omega^{-4}\right)
$$

where $A=8.1 \cdot 10^{-3} g^{2}, B=3.11 H_{1 / 3}^{-2}$, and $H_{1 / 3}$ is the significant wave height [37].
When a marine vessel is sailing in the open sea at a fixed speed, the encounter frequency is

$$
\omega_{e}=\omega-\frac{\omega^{2}}{g U \cos \beta},
$$

where $U$ is the sailing speed and $\beta$ is the wave-to-course angle. So the wave energy spectrum related to the encounter frequency is

$$
S\left(\omega_{e}\right)=\frac{S(\omega)}{1-2 \omega U \cos \beta / g} .
$$

According to the strip theory and equivalent energy division method, the disturbance moments of the yaw and roll dynamics can be calculated.

To verify the effectiveness of the proposed control scheme, the following control methodologies are demonstrated for comparison.

(1) Iterative learning observer based sliding mode controller (ILSMC): this is the observer based sliding mode control approach using iterative learning strategy proposed in the previous sections. In order to reduce the chattering phenomenon, a saturated function sat $(\cdot)$ is utilized instead of $\operatorname{sgn}(\cdot)$. The control parameters are listed as follows:

$$
\begin{aligned}
L & =\left[\begin{array}{ll}
11.58 & -2.85 \\
-2.75 & 22.94 \\
55.47 & 57.26 \\
75.91 & 54.89
\end{array}\right], \\
\mu_{1} & =\operatorname{diag}\left[\begin{array}{ll}
0.97 & 0.78
\end{array}\right], \\
\mu_{2} & =\left[\begin{array}{ll}
127.31 & 58.11 \\
52.15 & 49.82
\end{array}\right], \\
K & =\left[\begin{array}{ll}
11.12 & 3.14 \\
1.73 & 2.11
\end{array}\right], \\
K_{\tau} & =\left[\begin{array}{ll}
4.54 & 1.71 \\
0.63 & 0.49
\end{array}\right], \\
\alpha & =0.35, \\
\bar{e}_{d} & =0.07 .
\end{aligned}
$$

(2) Iterative learning observer with standard sliding mode controller (ILOSSMC): in this method, a standard sliding surface is used instead of the iterative learning sliding manifold to verify the advantage of the proposed control approach. In the ILOSSMC, $K_{\tau}=0$, and the other parameters are the same as the ILSMC.

(3) Linear extended state observer with standard sliding mode controller (LESOSSMC): in this method, the system model is linearized by an auxiliary feedback 

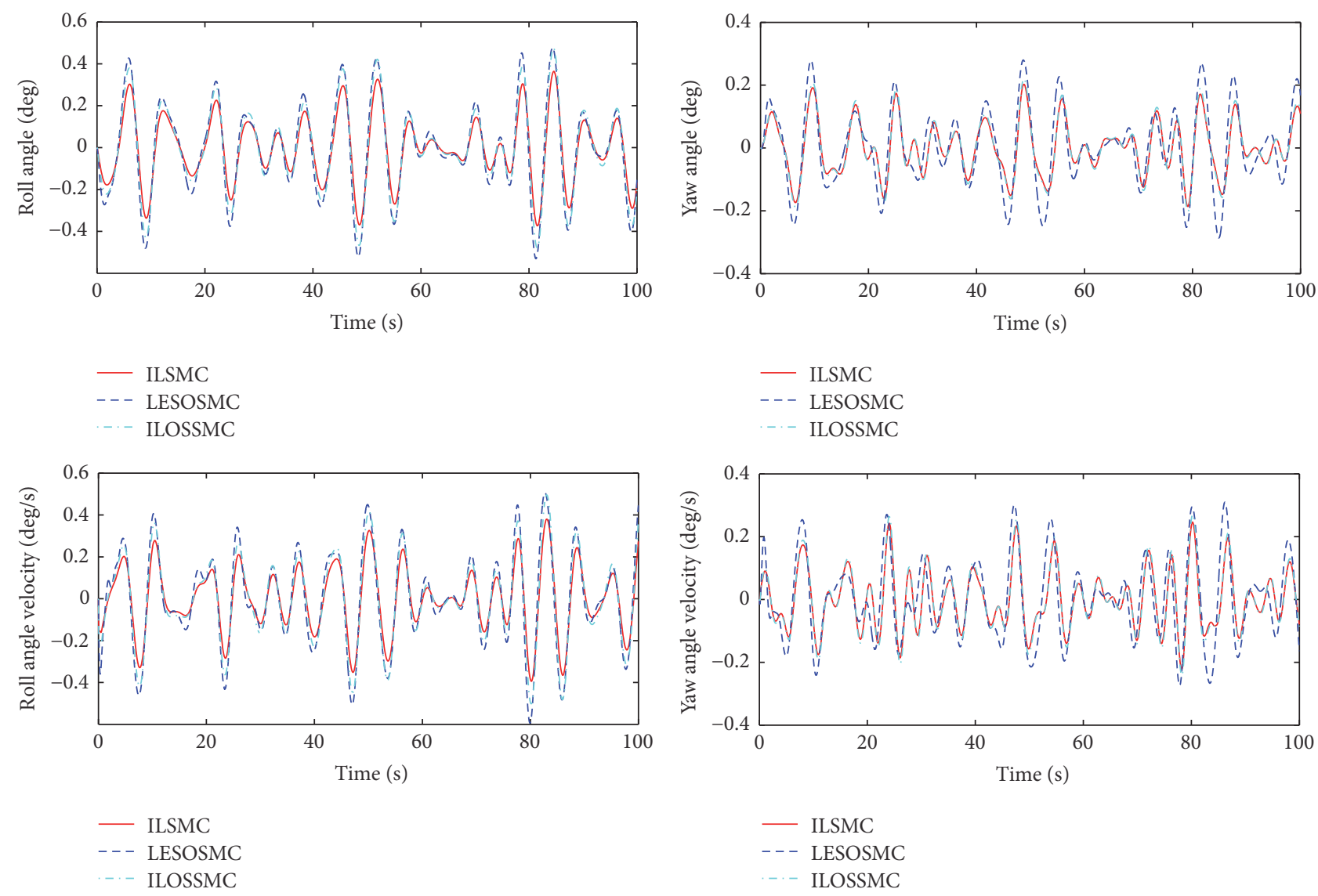

FIgURE 3: Stabilization effect of system states (Case 1).

linearization approach. Based on this approach, a linear extended state observer (LESO) is designed to estimate system states as well as the generalized disturbances. The sliding mode controller design is similar to the ILOSSMC. The LESO is designed as follows:

$$
\begin{aligned}
& e_{1}=x_{1}-\widehat{z}_{1}, \\
& \dot{\bar{z}}_{1}=\widehat{z}_{2}+l_{1} e_{1}, \\
& \dot{\bar{z}}_{2}=F_{0}\left(\widehat{z}_{1}, \widehat{z}_{2}\right)+\chi+z_{3}+l_{2} e_{1}, \\
& \dot{\bar{z}}_{3}=l_{3} e_{1},
\end{aligned}
$$

where $x_{1}$ is the system output, $\widehat{z}_{1}, \widehat{z}_{2}$ are the estimate values of $x_{1}, x_{2}$, and $z_{3}$ is the extended state for the estimate of the generalized disturbances. The parameters of the LESO are selected as follows: $l_{1}=$ $54, l_{2}=189$, and $l_{3}=3472$.

The above control schemes are tested individually for the course keeping of the FSHV in two typical cases, namely, Case 1 (sea state $3, H_{1 / 3}=1.5 \mathrm{~m}$ ) and Case 2 (sea state 5, $H_{1 / 3}=3.8 \mathrm{~m}$ ). Figures 3 and 4 show the stabilization of roll and yaw dynamics based on three control methods on the condition $H_{1 / 3}=1.5 \mathrm{~m}$ and $H_{1 / 3}=3.8 \mathrm{~m}$, respectively.
The rudder angle and aileron angle of the two cases are presented in Figures 5 and 6. From Figures 3-6, we can see that based on the online iterative optimization, the stabilization performance of the ILSMC is better than that of the LESOSSMC against wave disturbances, and the system consumption of the ILSMC does not increase. Comparing the ILSMC with the ILOSSMC, we can see that the iterative learning item in the sliding manifold (25) plays an important role in the system stabilization. Utilizing the learning item, the system control can be automatically regulated according to the tendency of the system trajectory, which decreases the conservation in control design.

As to the state estimate, Figures 7 and 8 show the real system state and the state estimate of the ILO and the LESO in Case 1, and Figures 9 and 10 present the system estimate in Case 2. It can be shown from Figures 7-10 that the estimate accuracy of the ILO is higher than that of the LESO. Because of the high-gain character of the LESO, the peak phenomenon will occur if the observer gain selected is too large, while this problem will not happen in the ILO. Because of the design of $\gamma(t)$ in the ILO, the estimating values can be updated dynamically according to the sample time $\tau$, which enhances the state estimate precision for the system. In addition, $\gamma(t)$ can detect the generalized disturbances and compensate them in the feedforward loop. The comparison of the disturbance estimate between the ILO and the LESO 

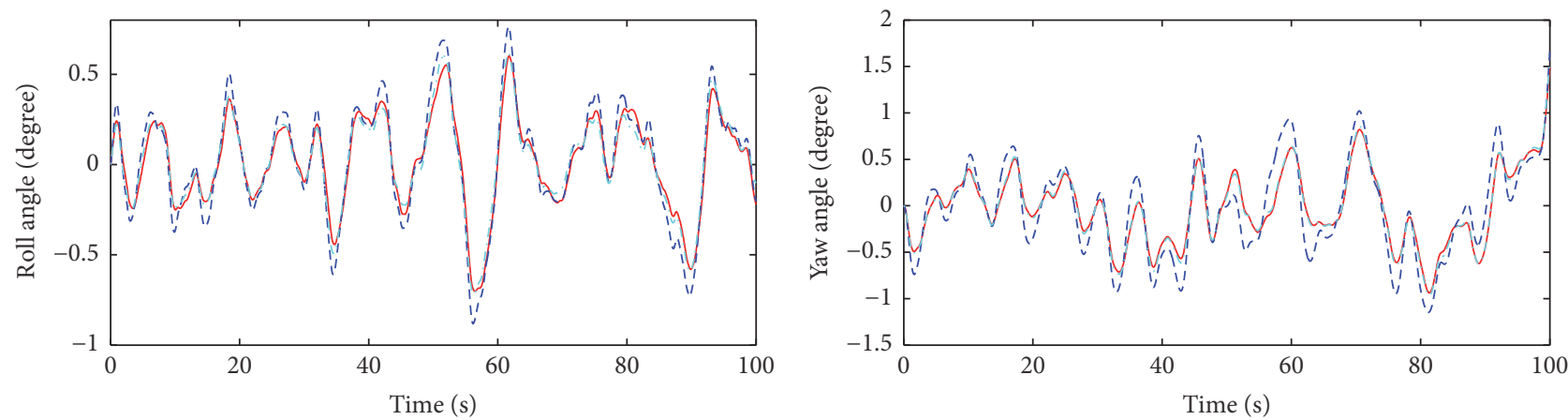

- ILSMC
-- LESOSMC
$\ldots$-.. ILOSSMC

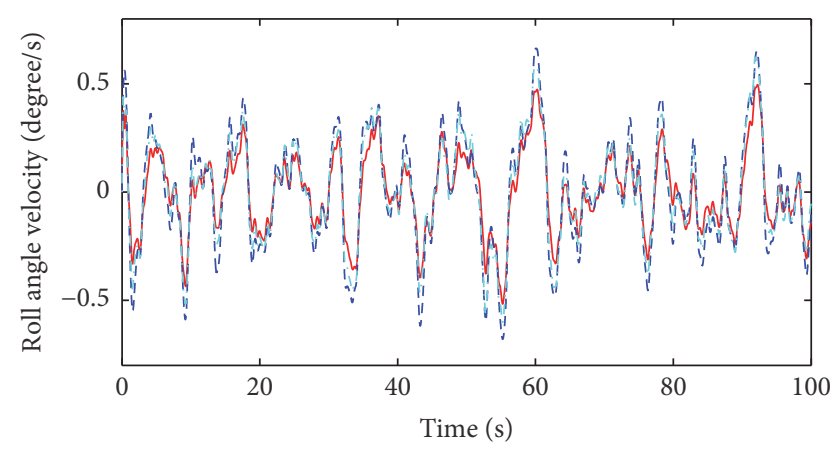

- ILSMC

- - - LESOSMC

ILOSSMC
- ILSMC

- - LESOSMC

ILOSSMC

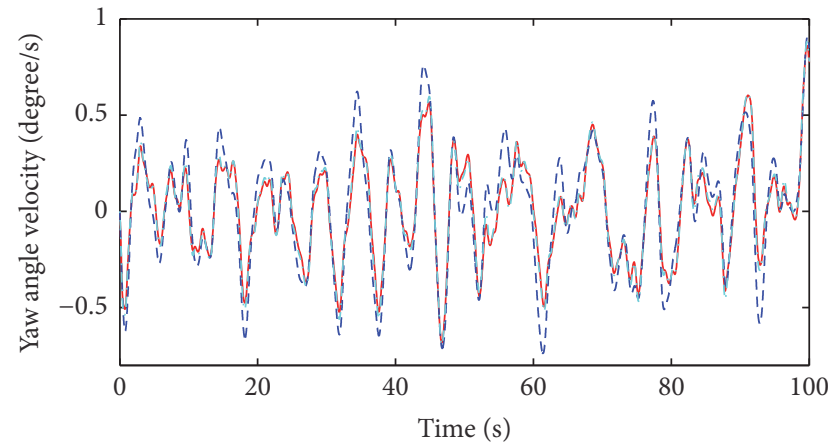

- ILSMC

- - LESOSMC

ILOSSMC

FIgURE 4: Stabilization effect of system states (Case 2).
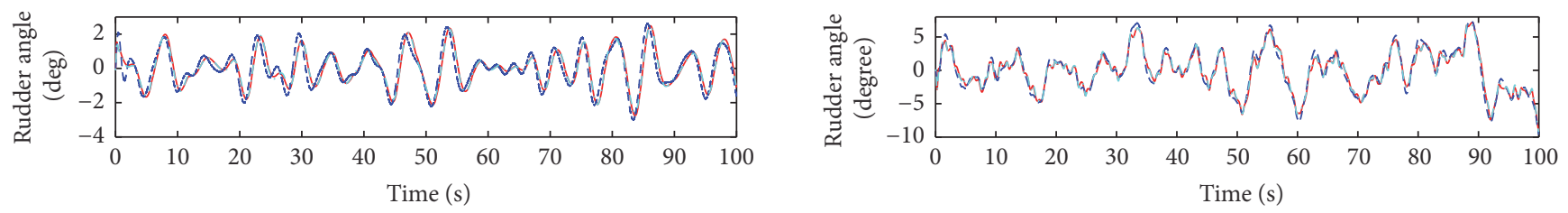

- ILSMC

- - - LESOSMC

- ILSMC

- - - LESOSMC

-.- ILOSSMC

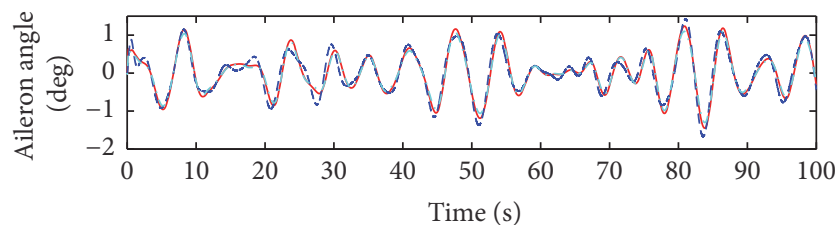

- ILSMC

- - LESOSMC

...- ILOSSMC

FIGURE 5: Control inputs of rudder and aileron (Case 1).

is illustrated in Figure 11 (Case 1) and Figure 12 (Case 2). It is illustrated that with the increase of the disturbances, the gaps in disturbances observing of the two methods become more obvious, which signifies the advantages of the ILO in severely perturbed systems. Using fixed observer gain, the ILO represents a self-adaptation property in state estimate, 

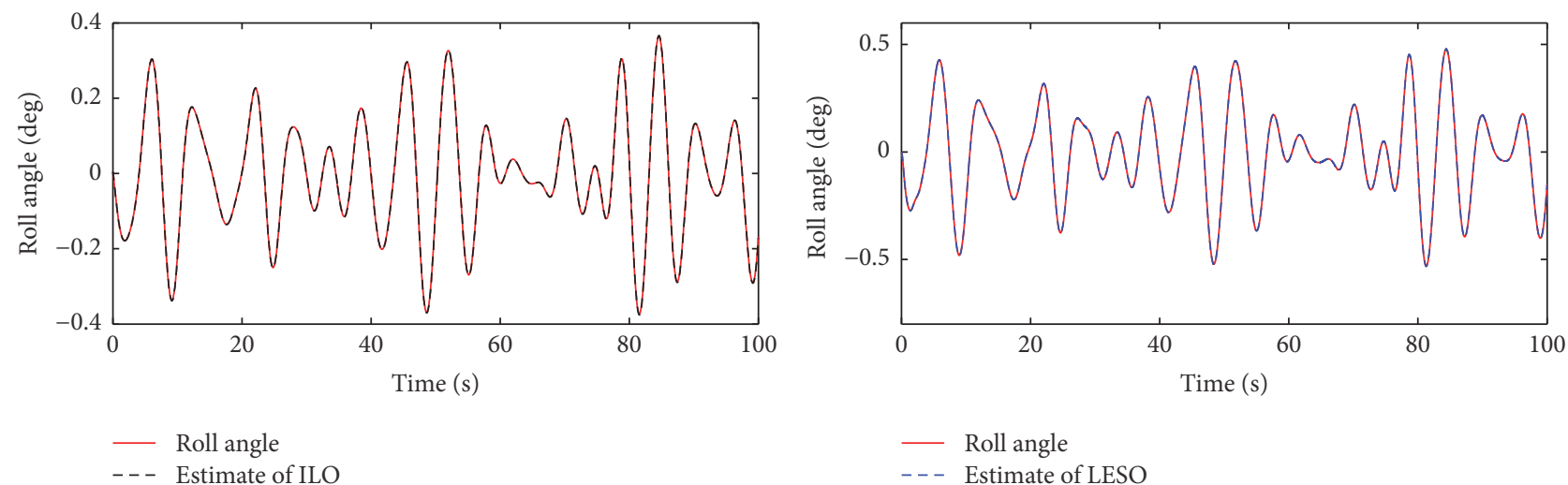

- - - Estimate of ILO
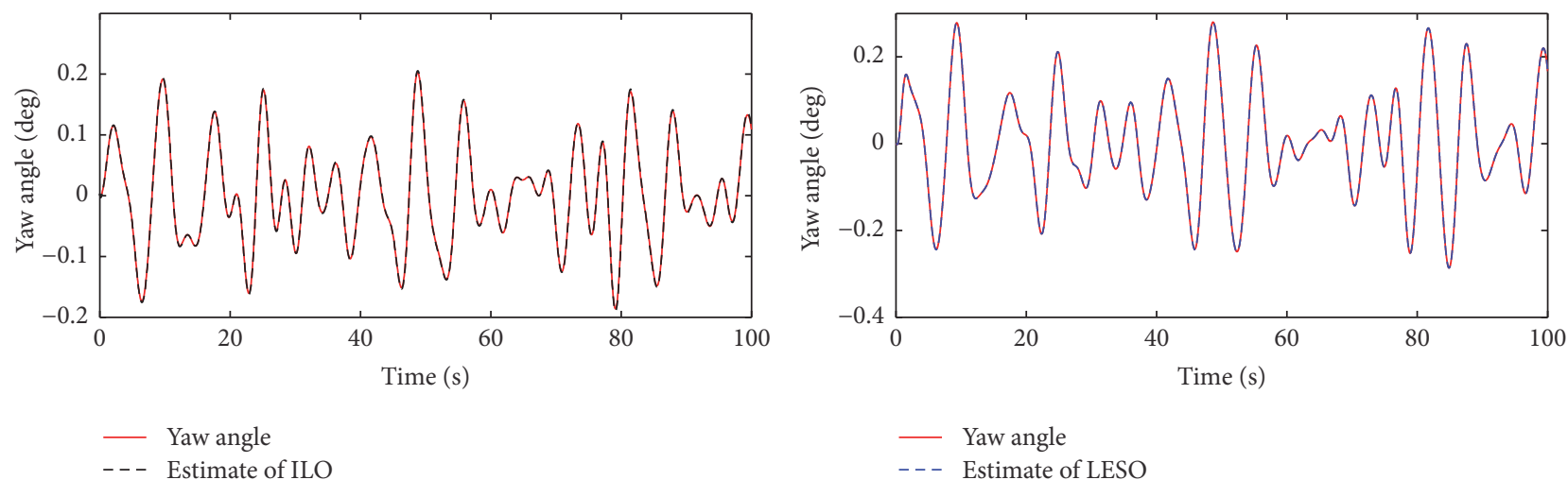

__ Yaw angle

_. - Estimate of LESO

FIGURE 7: Roll/yaw angle estimate performance (Case 1).
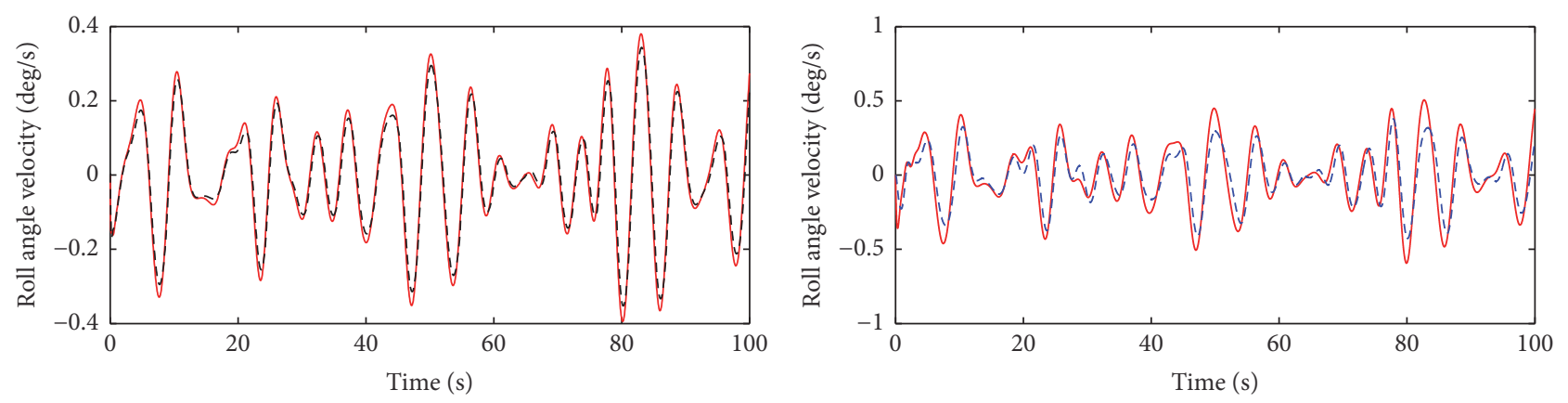

- Roll angle velocity

- - - Estimate of ILO

— Roll angle velocity

- - - Estimate of LESO
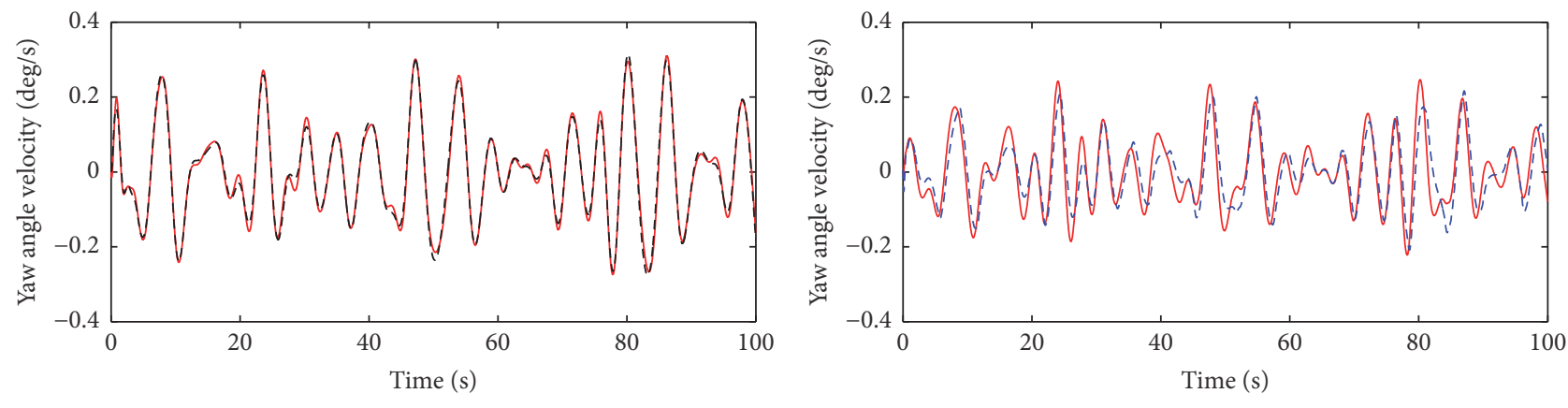

- Yaw angle velocity

_ Yaw angle velocity

- - Estimate of ILO

- - - Estimate of LESO

FIGURE 8: Angle velocity estimate performance (Case 1). 

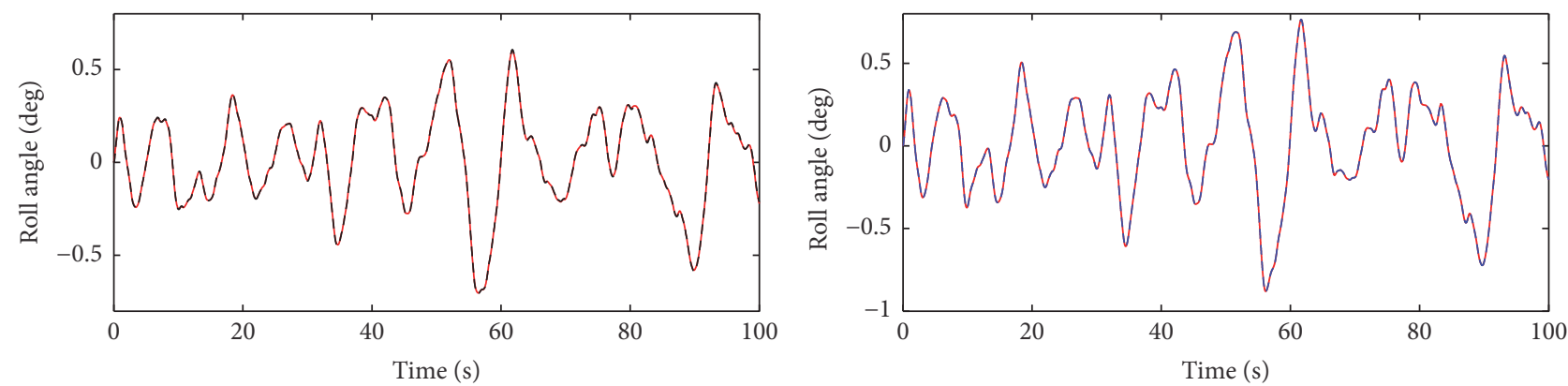

- Roll angle

- - - Estimate of ILO

- Roll angle

- - Estimate of LESO
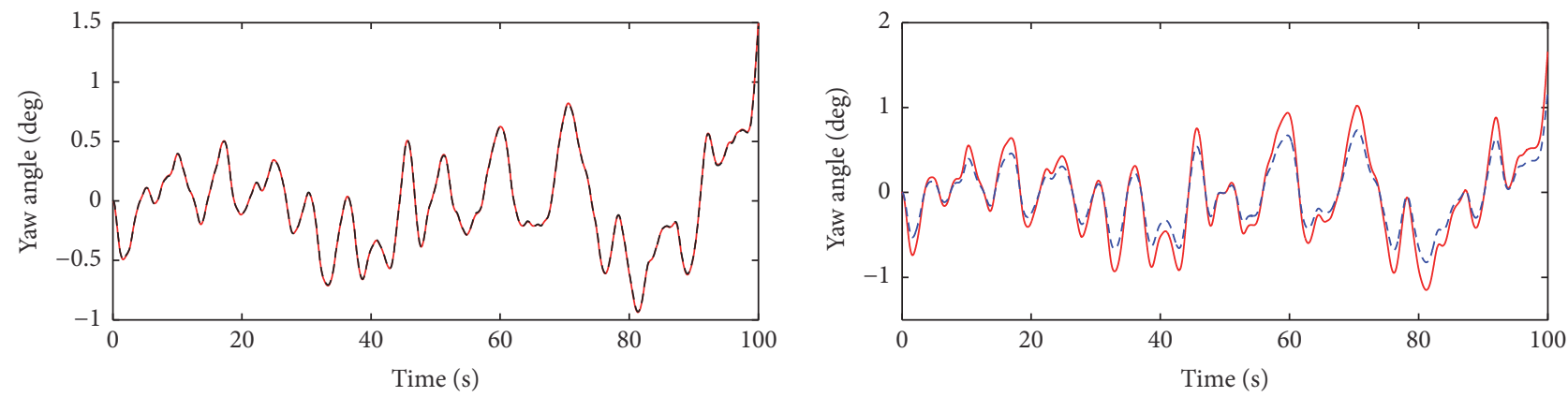

- Yaw angle

- - - Estimate of ILO

- Yaw angle

- - - Estimate of LESO

FIgURE 9: Roll/yaw angle estimate performance (Case 2).
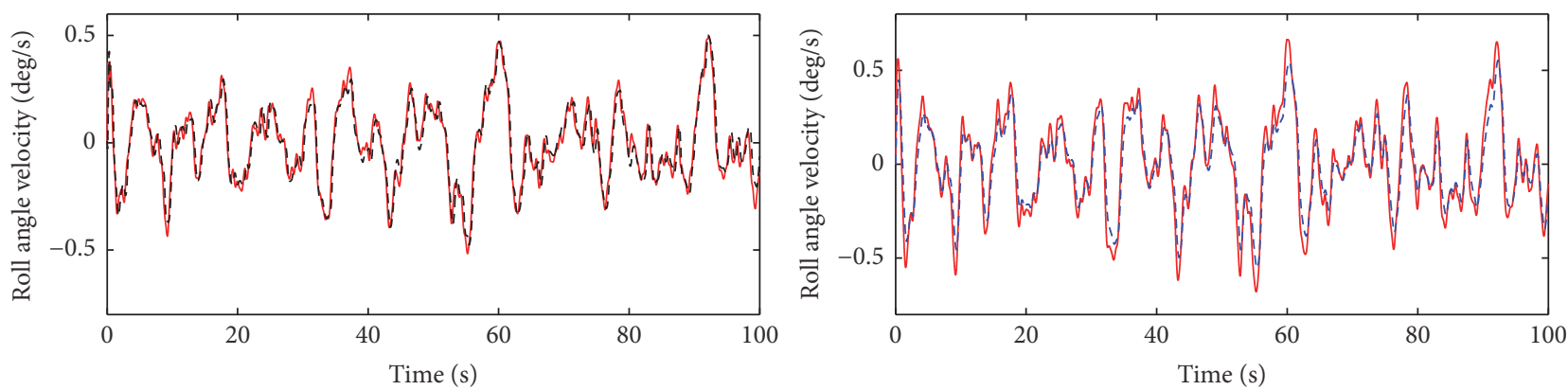

- Roll angle velocity

- - - Estimate value of ILO

- Roll angle velocity

- - - Estimate value of LESO
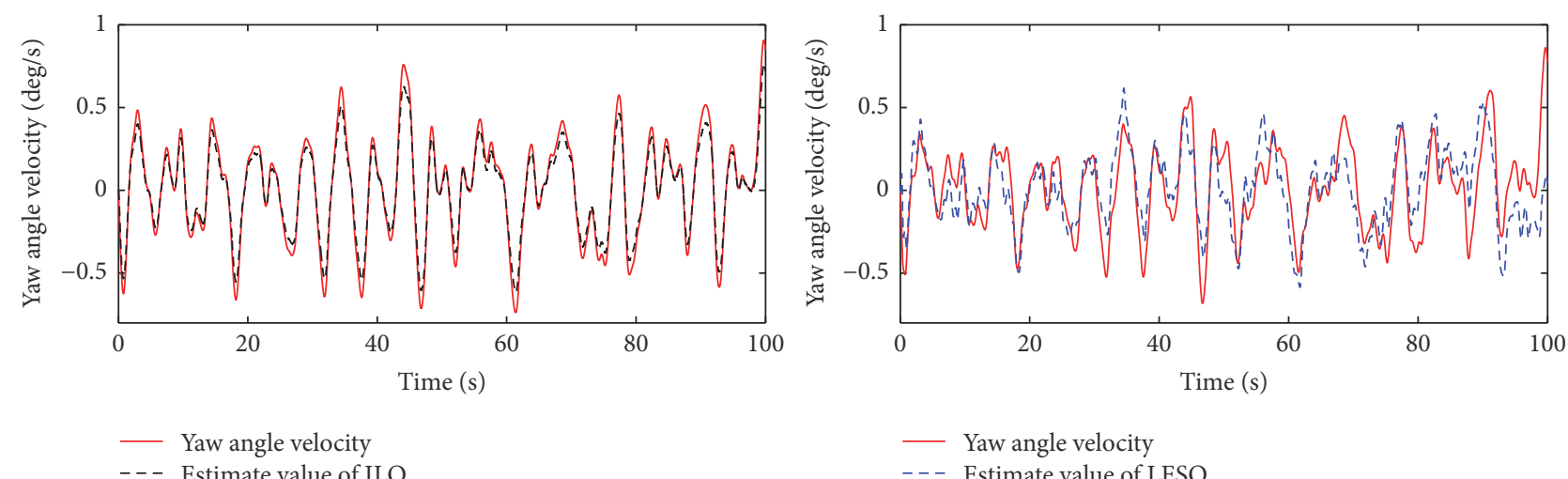

_ Yaw angle velocity

- - - Estimate value of LESO

FIgUre 10: Angle velocity estimate performance (Case 2). 


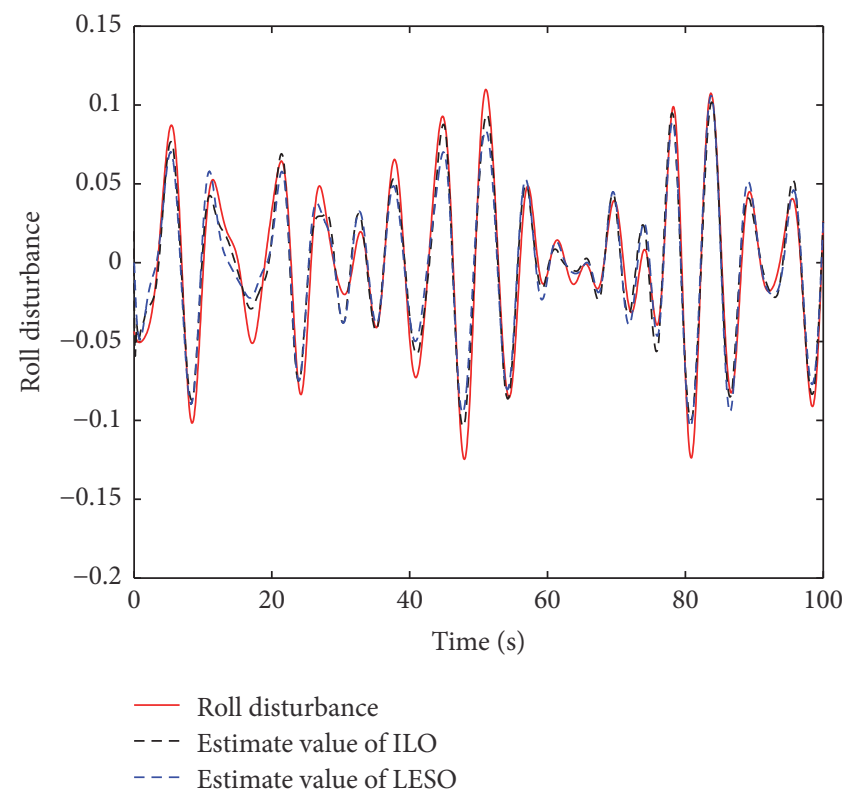

(a)

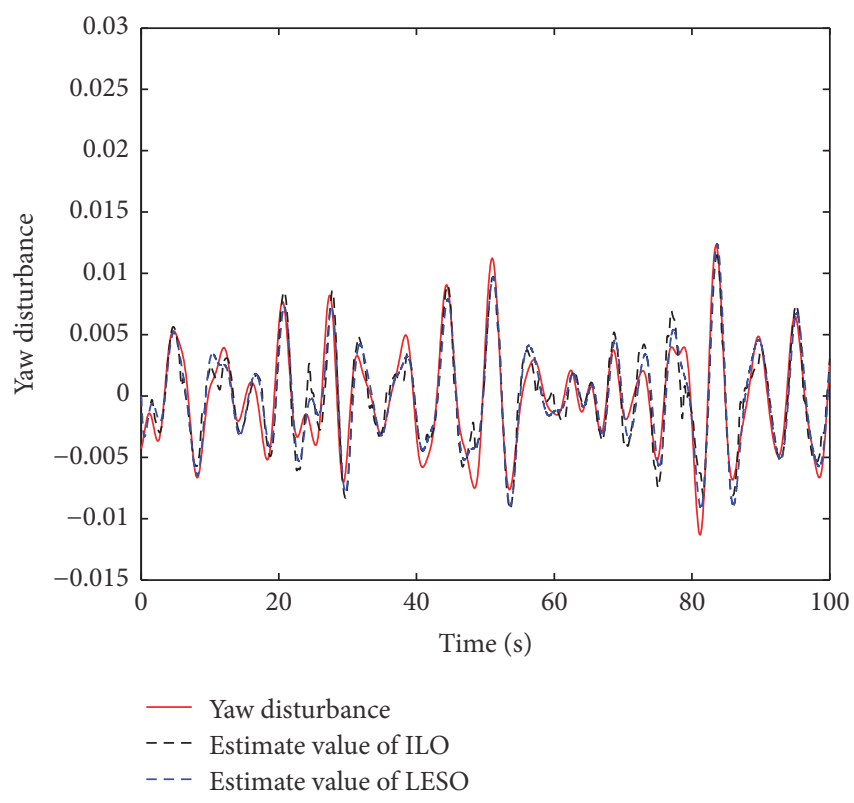

(b)

FIGURE 11: Disturbance estimate performance (Case 1): (a) the roll disturbance estimate; (b) the yaw disturbance estimate.

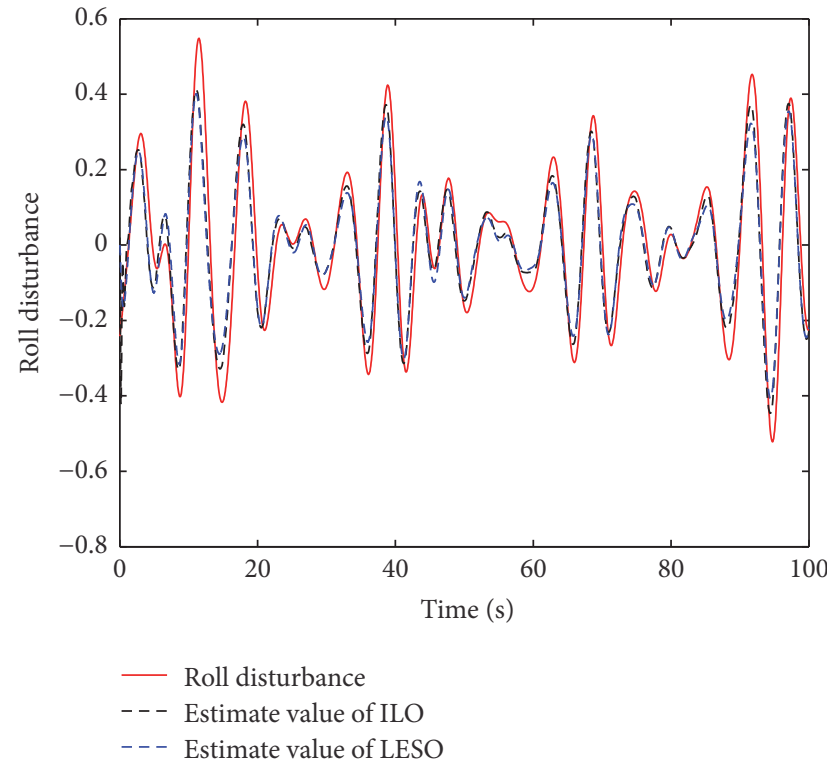

(a)

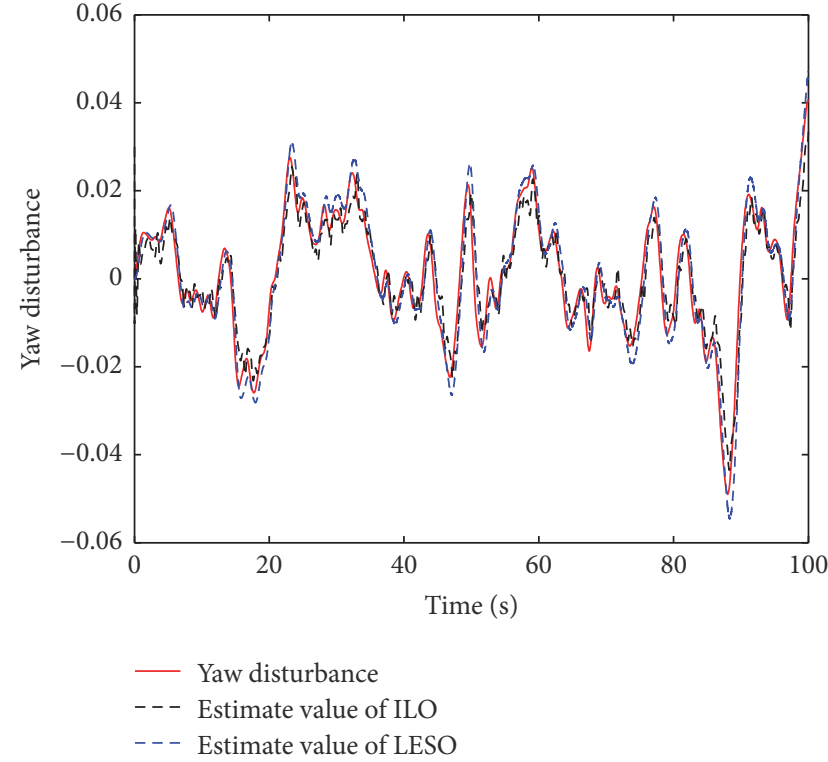

(b)

FIGURE 12: Disturbance estimate performance (Case 2): (a) the roll disturbance estimate; (b) the yaw disturbance estimate.

which achieves a better disturbance rejection performance than the LESO. The root mean square errors (RMSE) of the above state observers are listed in Table 2.

\section{Conclusion}

In this paper, an output feedback control scheme is investigated for the course keeping control of the fully submerged hydrofoil vessel based on an iterative learning strategy. An iterative learning observer is illustrated for the estimation of system states as well as the generalized disturbances. Then an iterative sliding model controller is established for the attitude stabilization of the fully submerged hydrofoil vessel. Based on the ILO, the disturbances can be estimated through the inner loop, and the iterative sliding mode controller attenuates the residual error of the estimated disturbances in the outer loop. Based on Lyapunov stability theory, uniformly ultimate boundedness of the overall closed-loop system is guaranteed. With the intervention of the iterative item, performance of the transient states can be improved for both state observer 
TABLE 2: Estimate performance comparison of the observers.

\begin{tabular}{cccccccc}
\hline RMSE & & $\widetilde{\phi}$ & $\widetilde{\psi}$ & $\widetilde{p}$ & $\tilde{r}$ & $\tilde{\tau}_{\text {droll }}$ & $\tilde{\tau}_{\text {dyaw }}$ \\
\hline \multirow{2}{*}{ Case 1 } & ILO & 0.164 & 0.088 & 0.161 & 0.092 & 0.048 & 0.004 \\
& LESO & 0.215 & 0.122 & 0.219 & 0.126 & 0.049 & 0.006 \\
Case 2 & ILO & 0.258 & 0.184 & 0.187 & 0.161 & 0.061 & 0.012 \\
& LESO & 0.317 & 0.298 & 0.258 & 0.214 & 0.063 & 0.013 \\
\hline
\end{tabular}

and controller. Comparative simulation results illustrate that the proposed approach achieves better estimate accuracy and disturbance rejection performance. The system conservation also decreases compared with conventional approaches. In future work, time-varying sampling time is to be considered based on the time scale and frequency characteristic of the system. And the control objective for the FSHV will extend to the kinematic level with goals such as path following and trajectory tracking.

\section{Conflicts of Interest}

The authors declare that there are no conflicts of interest regarding the publication of this paper.

\section{Acknowledgments}

This work is supported by National Natural Science Foundation of China under Grant 51579047.

\section{References}

[1] Y. Saito and T. Ikebuchi, "Fully submerged hydrofoil vessel," in Proceedings of the 7th Marine Dynamics Symposium on Prediction of Seakeeping Qualities of High-Speed Vessel, pp. 107141, 1990.

[2] H. Imamura, Y. Saito, and M. Asao, "Automatic control system for jetfoil," Kawasaki Technical Review, no. 107, pp. 1-9, 1990.

[3] S. Liu, C. Xu, and Y. Wang, "Disturbance rejection control for the course keeping of the fully-submerged hydrofoil craft," in Proceedings of the 35th Chinese Control Conference, CCC 2016, pp. 747-751, IEEE, Chengdu, China, July 2016.

[4] S.-H. Kim and H. Yamato, "On the design of a longitudinal motion control system of a fully-submerged hydrofoil craft based on the optimal preview servo system," Ocean Engineering, vol. 31, no. 13, pp. 1637-1653, 2004.

[5] K. D. Do and J. Pan, "State- and output-feedback robust pathfollowing controllers for underactuated ships using SerretFrenet frame," Ocean Engineering, vol. 31, no. 5-6, pp. 587-613, 2004.

[6] L. J. Zhang, H. M. Jia, and X. Qi, "NNFFC-adaptive output feedback trajectory tracking control for a surface ship at high speed," Ocean Engineering, vol. 38, no. 13, pp. 1430-1438, 2011.

[7] S.-H. Kim and H. Yamato, "An experimental study of the longitudinal motion control of a fully submerged hydrofoil model in following seas," Ocean Engineering, vol. 31, no. 5-6, pp. 523-537, 2004.

[8] A. Rosales and I. Boiko, "Disturbance attenuation for systems with second-order sliding modes via linear compensators," IET Control Theory \& Applications, vol. 9, no. 4, pp. 526-537, 2015.
[9] Y. Feng, F. Han, and X. Yu, "Chattering free full-order slidingmode control," Automatica. A Journal of IFAC, the International Federation of Automatic Control, vol. 50, no. 4, pp. 1310-1314, 2014.

[10] J. D. Sánchez-Torres, A. Navarrete-Guzman, G. Rubio-Astorga, and A. G. Loukianov, "High order integral nested sliding mode control," in Proceedings of the 13th International Workshop on Variable Structure Systems, VSS 2014, IEEE, Nantes, France, July 2014.

[11] S.-W. Ji, V. P. Bui, B. Balachandran, and Y.-B. Kim, "Robust control allocation design for marine vessel," Ocean Engineering, vol. 63, pp. 105-111, 2013.

[12] J. Du, Y. Yang, D. Wang, and C. Guo, "A robust adaptive neural networks controller for maritime dynamic positioning system," Neurocomputing, vol. 110, pp. 128-136, 2013.

[13] N. E. Kahveci and P. A. Ioannou, "Adaptive steering control for uncertain ship dynamics and stability analysis," Automatica. A Journal of IFAC, the International Federation of Automatic Control, vol. 49, no. 3, pp. 685-697, 2013.

[14] P. M. Patre, W. MacKunis, M. Johnson, and W. E. Dixon, "Composite adaptive control for Euler-Lagrange systems with additive disturbances," Automatica. A Journal of IFAC, the International Federation of Automatic Control, vol. 46, no. 1, pp. 140-147, 2010.

[15] H. Hammouri, G. Bornard, and K. Busawon, "High gain observer for structured multi-output nonlinear systems," Institute of Electrical and Electronics Engineers. Transactions on Automatic Control, vol. 55, no. 4, pp. 987-992, 2010.

[16] L. Wang and J. Su, "Robust Disturbance Rejection Control for Attitude Tracking of an Aircraft," IEEE Transactions on Control Systems Technology, vol. 23, no. 6, pp. 2361-2368, 2015.

[17] D. Ginoya, P. D. Shendge, and S. B. Phadke, "Sliding mode control for mismatched uncertain systems using an extended disturbance observer," IEEE Transactions on Industrial Electronics, vol. 61, no. 4, pp. 1983-1992, 2014.

[18] A. Mohammadi, M. Tavakoli, H. J. Marquez, and F. Hashemzadeh, "Nonlinear disturbance observer design for robotic manipulators," Control Engineering Practice, vol. 21, no. 3, pp. 253-267, 2013.

[19] H. Sun, S. Li, J. Yang, and L. Guo, "Non-linear disturbance observer-based back-stepping control for airbreathing hypersonic vehicles with mismatched disturbances," IET Control Theory and Applications, vol. 8, no. 17, pp. 1852-1865, 2014.

[20] S. Xingling and W. Honglun, "Back-stepping active disturbance rejection control design for integrated missile guidance and control system via reduced-order ESO," ISA Transactions, vol. 57, pp. 10-22, 2015.

[21] W. H. Chen, "Nonlinear Disturbance Observer-Enhanced Dynamic Inversion Control of Missiles," Journal of Guidance Control \& Dynamics, vol. 26, no. 1, pp. 161-166, 2012.

[22] J. Wang, S. Li, J. Yang, B. Wu, and Q. Li, "Extended state observer-based sliding mode control for PWM-based DC-DC buck power converter systems with mismatched disturbances," IET Control Theory and Applications, vol. 9, no. 4, pp. 579-586, 2015.

[23] C. Wang, X. Li, L. Guo, and Y. W. Li, "A nonlinear-disturbanceobserver-based DC-Bus voltage control for a hybrid AC/DC microgrid," IEEE Transactions on Power Electronics, vol. 29, no. 11, pp. 6162-6177, 2014.

[24] M. Ekramian, F. Sheikholeslam, S. Hosseinnia, and M. J. Yazdanpanah, "Adaptive state observer for Lipschitz nonlinear 
systems," Systems and Control Letters, vol. 62, no. 4, pp. 319-323, 2013.

[25] Y. Li and S. Tong, "Adaptive Fuzzy Output-Feedback Stabilization Control for a Class of Switched Nonstrict-Feedback Nonlinear Systems," IEEE Transactions on Cybernetics, 2016.

[26] S. Tong, Y. Li, and S. Sui, "Adaptive fuzzy tracking control design for uncertain non-strict feedback nonlinear systems," IEEE Transactions on Fuzzy Systems, vol. 24, no. 6, pp. 14411454, 2016.

[27] Y. Li, S. Tong, L. Liu, and G. Feng, "Adaptive output-feedback control design with prescribed performance for switched nonlinear systems," Automatica. A Journal of IFAC, the International Federation of Automatic Control, vol. 80, pp. 225-231, 2017.

[28] S. Tong, Y. Li, and S. Sui, "Adaptive Fuzzy Output Feedback Control for Switched Nonstrict-Feedback Nonlinear Systems With Input Nonlinearities," IEEE Transactions on Fuzzy Systems, vol. 24, no. 6, pp. 1426-1440, 2016.

[29] N. Sakamoto, B. Rehák, and K. Ueno, "Nonlinear Luenberger observer design via invariant manifold computation," IFAC Proceedings Volumes, vol. 47, no. 3, pp. 37-42, 2014.

[30] A. Alessandri and A. Rossi, "Increasing-gain observers for nonlinear systems: stability and design," Automatica. A Journal of IFAC, the International Federation of Automatic Control, vol. 57, pp. 180-188, 2015.

[31] C. Mu and C. Sun, "A new finite time convergence condition for super-twisting observer based on Lyapunov analysis," Asian Journal of Control, vol. 17, no. 3, pp. 1050-1060, 2015.

[32] J. M. Daly and D. W. L. Wang, "Output feedback sliding mode control in the presence of unknown disturbances," Systems and Control Letters, vol. 58, no. 3, pp. 188-193, 2009.

[33] H. v. Grip, A. Saberi, and T. A. Johansen, "Observers for interconnected nonlinear and linear systems," Automatica. A Journal of IFAC, the International Federation of Automatic Control, vol. 48, no. 7, pp. 1339-1346, 2012.

[34] M. Ghanes, J. De Leon, and J.-P. Barbot, "Observer design for nonlinear systems under unknown time-varying delays," Institute of Electrical and Electronics Engineers. Transactions on Automatic Control, vol. 58, no. 6, pp. 1529-1534, 2013.

[35] M. Ekramian, F. Sheikholeslam, S. Hosseinnia, and M. J. Yazdanpanah, "Adaptive state observer for Lipschitz nonlinear systems," Systems and Control Letters, vol. 62, no. 4, pp. 319-323, 2013.

[36] M. H. Holakooie, M. Ojaghi, and A. Taheri, "Full-order Luenberger observer based on fuzzy-logic control for sensorless field-oriented control of a single-sided linear induction motor," ISA Transactions, vol. 60, pp. 96-108, 2016.

[37] T. I. Fossen, Handbook of Marine Craft Hydrodynamics and Motion Control, John Wiley \& Sons, West Sussex, UK, 2011.

[38] H. K. Khalil, Nonlinear Systems, Prentice-Hall, Inc, Upper Saddle River, NJ, USA, 3rd edition, 2002.

[39] R. P. Panneer Selvam and S. K. Bhattacharyya, "System identification of a coupled two DOF moored floating body in random ocean waves," Journal of Offshore Mechanics and Arctic Engineering, vol. 128, no. 3, pp. 191-202, 2006. 


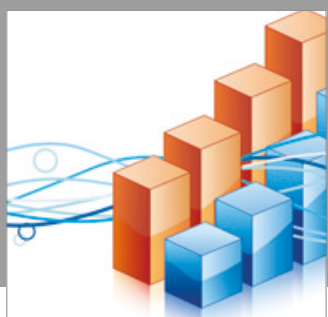

Advances in

Operations Research

vatersals

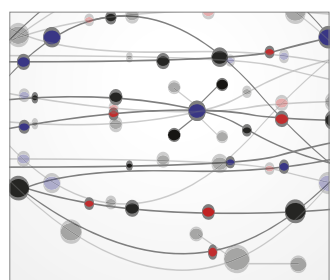

\section{The Scientific} World Journal
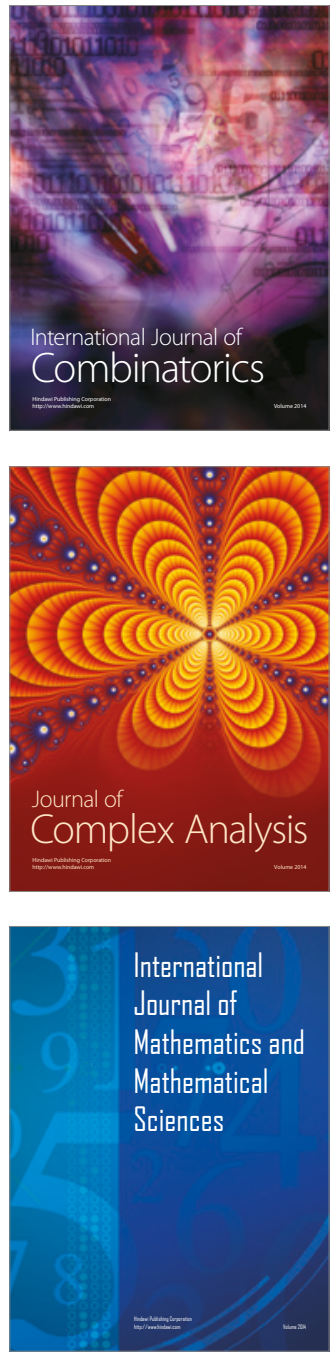
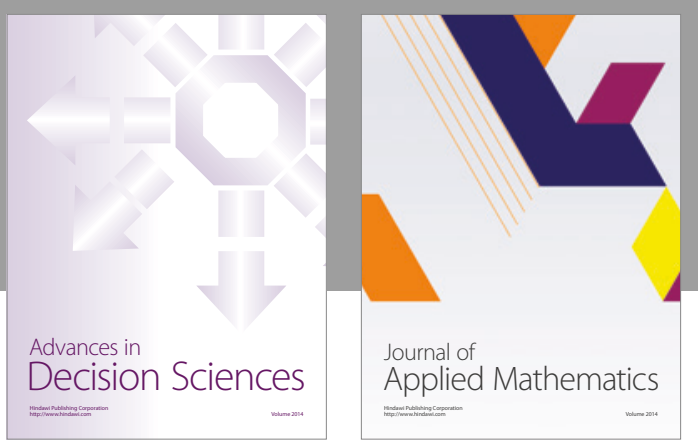

Algebra

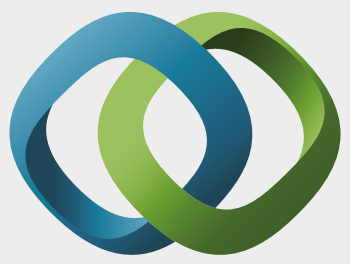

\section{Hindawi}

Submit your manuscripts at

https://www.hindawi.com
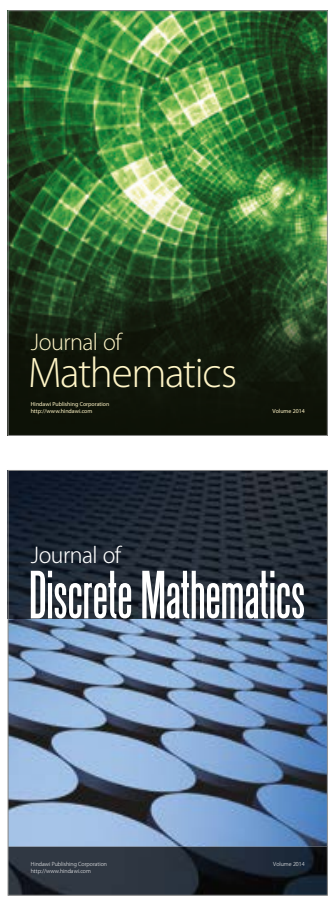

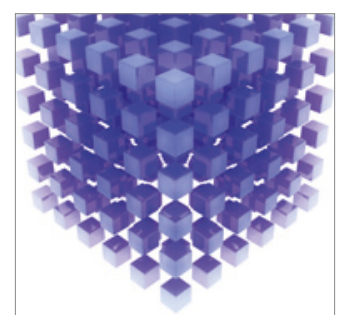

Mathematical Problems in Engineering
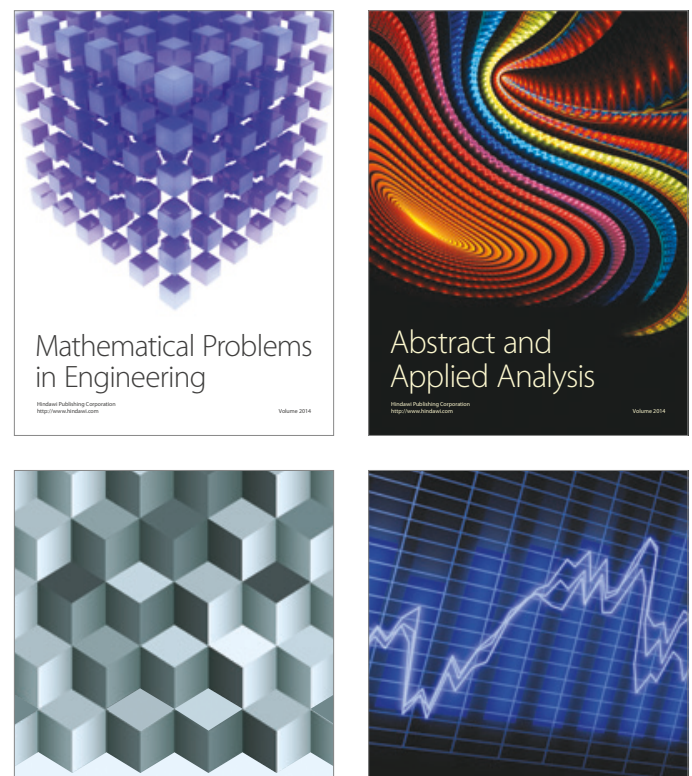

Journal of

Function Spaces

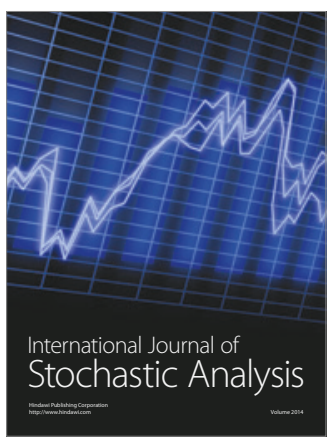

Probability and Statistics
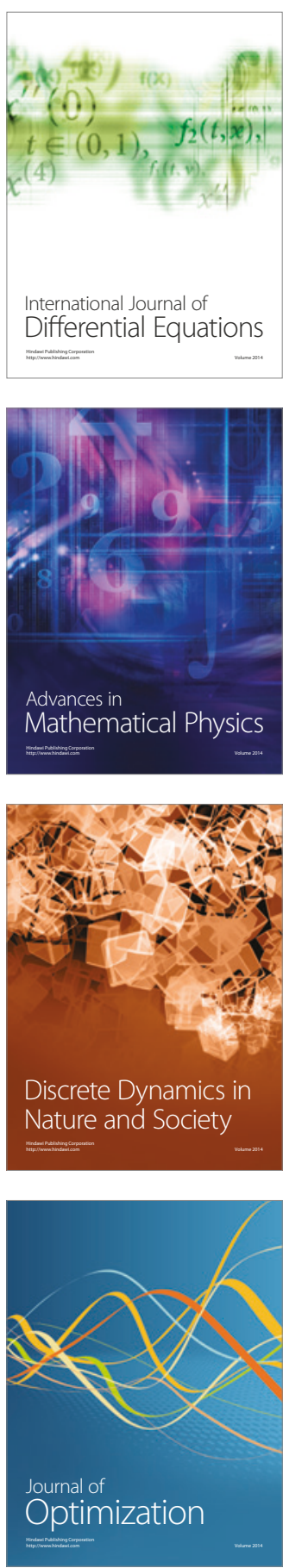